\title{
Prolonged dimethylsulphoxide treatment in 13 patients with systemic amyloidosis
}

\author{
MORDCHAI RAVID, JEREMIAH SHAPIRA, RUTH LANG, \\ AND IGAL KEDAR \\ From the Department of Medicine, Meir Hospital, and the Heller Institute of Medical Research, Sackler School \\ of Medicine, Tel Aviv University, Israel
}

SUMMARY Continuous oral dimethylsulphoxide (DMSO) treatment (7-15 g/day) was given to 3 patients with amyloidosis of familial Mediterranean fever (FMF), 3 patients with idiopathic amyloidosis, and 7 patients with secondary amyloidosis. The nephrotic syndrome and various degrees of renal insufficiency were the major clinical manifestation in all cases. Renal function was used as the main parameter for evaluation of therapy. DMSO treatment for 7-16 months produced no effect in the FMF patients and in the patients with idiopathic amyloidosis; they all ran the predictable clinical course of their disease and either died of cardiac failure or have been maintained on chronic haemodialysis. In the 7 patients with secondary amyloidosis an unequivocal improvement of renal function was observed following 3-6 months of DMSO treatment. It was shown by a $30-100 \%$ rise of creatinine clearance and a decline in proteinuria. This new equilibrium has been maintained as long as DMSO was administered. No serious side effects of DMSO were encountered. Mild nausea and an unpleasant breath odour were the patients' main concern. We conclude that a therapeutic trial with oral DMSO is warranted in all patients with secondary amyloidosis. This treatment is unpleasant but bears no exceptional risks. It may significantly prolong life, though its effects on amyloid deposits themselves is doubtful.

Systemic amyloidosis is almost invariably fatal. Survival from the time of diagnosis ranges from several months in myeloma-associated amyloidosis to several years in secondary amyloidosis. Sporadic cases of regression of amyloidosis were reported to follow the eradication of a chronic inflammatory disease. ${ }^{1}$ In some patients with stable rheumatoid arthritis the degree of renal damage may remain constant for many years. ${ }^{2}$ Usually, however, amyloidosis runs a fairly predictable downhill course. Death usually results from end-stage renal failure or cardiac disease.

Continuous colchicine administration prevents the development of amyloidosis in familial Mediterranean fever and may also arrest the progress of an already existing disease when instituted at an early stage as long as renal function is normal. ${ }^{34}$ Rarely myeloma-associated amyloidosis was reported to respond to cytotoxic agents. ${ }^{5}$ More often, however, the progress of amyloidosis is unaffected. ${ }^{6}$ For the

Accepted for publication 20 October 1981.

Correspondence to Dr M Ravid, Department of Medicine, Meir Hospital, Kfar Saba 44 281, Israel. majority of patients with early amyloidosis and for all patients with advanced disease no cure is as yet available. Dimethyl sulphoxide (DMSO), an industrial solvent first introduced into the treatment of amyloidosis by Isobe and Osserman, ${ }^{7}$ causes partial or total disappearance of experimentally induced amyloid deposits in mice me $^{7-9}$ and of genetic AA amyloidosis in the duck. ${ }^{10}$ Therapeutic trials on a small number of patients indicated that prolonged treatment with this agent may be effective in certain types of systemic amyloidosis. ${ }^{11-13}$

The following report summarises our experience of prolonged DMSO treatment in 13 patients with systemic amyloidosis.

\section{Patients and methods}

The trial included 13 patients with acquired systemic amyloidosis, 3 of whom had familial Mediterranean fever (FMF) and 3 long-standing rheumatoid arthritis of 7 to 15 years' duration. Chronic osteomyelitis, inactive cavitary pulmonary tuberculosis, bronchiectasis, and ankylosing spondylitis were each present in 
one patient. In the 3 remaining patients no underlying disease could be identified. Systemic amyloidosis was assumed to be present in the FMF patients with nephrotic syndrome. In one of these patients a renal biopsy was performed at another hospital and abundant amyloid deposition was indeed found. In all other patients the diagnosis of amyloidosis was established by renal biopsy and polarisation microscopy of Congo red stained slides. Biopsy specimens from the 3 patients with clinically idopathic amyloidosis were examined after treatment with potassium permanganate according to the method of Wright et al. ${ }^{14}$; one patient showed permanganate sensitivity and 2 had resistant amyloid deposits. Immunoelectrophoresis of serum and urine failed to disclose monoclonal gammopathy or Bence-Jones proteinuria. The exact nature of the amyloid in these patients was therefore undetermined.

Renal involvement manifested by a nephrotic syndrome constituted the clinical presentation of amyloidosis in all our patients. Only one patient with FMF and one with rheumatoid arthritis had normal renal function prior to treatment. In the other 11 , plasma creatinine values were $2-5 \mathrm{mg} / \mathrm{dl}(177-442$ $\mu \mathrm{mol} / \mathrm{l})$ or higher. The patients were followed up at monthly intervals. The laboratory tests included complete blood counts, liver enzymes, bilirubin, haptoglobin, plasma proteins, cholesterol, electrolytes, calcium and phosphate, blood urea, plasma creatinine clearance, and urine analysis. Symptomatic treatment with diuretics and nonsteroidal antiinflammatory drugs was given when indicated. The FMF patients received colchicine $1-1.5 \mathrm{mg}$ daily.
Dimethyl sulphoxide (DMSO) was obtained as a pure $100 \%$ solution from Sigma Chemical Co. (St Louis, Mo, USA) It was administered orally to all patients as a $10 \%$ solution in fruit juice. The daily dose was $7 \cdot 5-10 \mathrm{~g}$ in the first 5 patients and $15 \mathrm{~g}$ in the others; it was given in 3 divided doses shortly before meals.

All the patients included in this report completed at least 7 months of uninterrupted treatment. Informed consent was obtained from all.

\section{Results}

\section{FMF AMYLOIDOSIS}

The results of DMSO treatment in these patients were disappointing. The 3 patients, a female and 2 males aged 19-25 years, presented with a nephrotic syndrome of 1-4 years' duration. DMSO was given for 10-12 months, $7 \cdot 5 \mathrm{~g} /$ day to the first patient, and $10 \mathrm{~g} /$ day to the other 2 . They all ran the predictable course of their disease without any apparent effect on either the proteinuria or renal function. The relevant data are presented in Table 1 . All 3 patients subsequently developed end-stage renal failure and are at present maintained on chronic haemodialysis.

\section{SECONDARY AMYLOIDOSIS}

The 3 patients with rheumatoid arthritis were 2 ? females and one male aged $42-63$ years. They were all seropositive with marked joint deformities. Previous treatment included nonsteroidal antiinflammatory drugs and steroids. Two patients had received chrysotherapy and one patient had received

Table 1 DMSO treatment in 3 patients with FMF amyloidosis. The downhill natural course of the disease was unaltered by this treatment

\begin{tabular}{|c|c|c|c|c|c|c|c|c|c|c|}
\hline \multirow[t]{2}{*}{ Patient } & \multirow[t]{2}{*}{ Cr.cl. ${ }^{*}$} & \multirow[t]{2}{*}{ Prot. ${ }^{\dagger}$} & \multicolumn{2}{|c|}{2 Months } & \multicolumn{2}{|c|}{6 Months } & \multicolumn{2}{|c|}{10 Months } & \multicolumn{2}{|c|}{12 Months } \\
\hline & & & Cr.cl. & Prot. & Cr.cl. & Prot. & Cr.cl. & Prot. & Cr.cl. & Prot. \\
\hline 1 & 80 & 15 & 74 & 16 & 71 & 22 & 62 & 12 & 20 & 8 \\
\hline 2 & 34 & 10 & 28 & 14 & 16 & 8 & 21 & 17 & - & - \\
\hline 3 & 16 & 12 & 18 & 20 & 12 & 7 & 8 & 10 & - & - \\
\hline
\end{tabular}

${ }^{*}$ Cr.cl. = creatinine clearance, $\mathrm{ml} / \mathrm{min}$.

+Prot. $=$ proteinuria, $\mathrm{g} / 24 \mathrm{~h}$.

Table 2 The course of renal amyloidosis in 3 patients with rheumatoid arthritis treated by oral DMSO 15 g/day. There was a gradual decline in proteinuria and an increase of creatinine clearance, together with a marked clinical improvement of signs of the nephrotic syndrome

\begin{tabular}{|c|c|c|c|c|c|c|c|c|c|c|c|c|}
\hline \multirow[t]{2}{*}{ Patient } & \multirow[t]{2}{*}{ Sex } & \multirow[t]{2}{*}{ Age } & \multirow{2}{*}{$\begin{array}{l}\text { Duration } \\
\text { of } R A, y r\end{array}$} & \multicolumn{3}{|l|}{ Time 0} & \multicolumn{3}{|c|}{6 Months } & \multicolumn{3}{|c|}{10 Months } \\
\hline & & & & P.cr.* & Cr.cl. & Prot. & P.cr. & Cr.cl. & Prot. & P.Cr. & Cr.cl. & Prot. \\
\hline 4 & $\mathbf{F}$ & 42 & 7 & 0.9 & 86 & 20 & $1 \cdot 1$ & 88 & 3 & $1 \cdot 0$ & 84 & $1 \cdot 5$ \\
\hline 5 & $\mathbf{F}$ & 54 & 12 & $4 \cdot 5$ & 26 & 8 & 3 & 35 & 4 & $2 \cdot 6$ & 38 & 3 \\
\hline 6 & $\mathbf{M}$ & 56 & 15 & $4 \cdot 8$ & 25 & $6 \cdot 5$ & $2 \cdot 7$ & 38 & $2 \cdot 5$ & $2 \cdot 5$ & 43 & 3 \\
\hline
\end{tabular}

The laboratory results given in this table are the average of 3 determinations done on 3 subsequent days.

* P.cr. = plasma creatinine.

For other abbreviations see Table 1. 
D-penicillamine. One patient was nephrotic with preserved renal function, and 2 had renal failure. During the first 10 months of oral DMSO treatment (15 g/day) some improvement of renal function was observed in all 3 patients, manifested by a decline in proteinuria, a modest rise of serum albumin, and an increase of creatinine clearance in the 2 patients in whom it had been initially impaired (Table 2). From the 11th month onwards the DMSO was given on alternate days and the dose was reduced to $10 \mathrm{~g} /$ day. Patient 5 was seen only once on a follow-up visit 4 months later. The renal functions were stable: creatinine $2.3 \mathrm{mg} / \mathrm{dl}(203 \mu \mathrm{mol} / \mathrm{l})$, blood urea 57 $\mathrm{mg} / \mathrm{dl}(9.5 \mathrm{mmol} / \mathrm{l})$, albumin $3.4 \mathrm{~g} / \mathrm{dl}(34 \mathrm{~g} / \mathrm{l})$, proteinuria $2 \mathrm{~g} / 24 \mathrm{~h}$.

Patient 4 has been on regular follow-up for 26 months. She continues to have mild proteinuria of 1-3 g/24 h and has shown no deterioration of renal function. Her arthritis is inactive and requires only occasional analgesic therapy. Patient 6 was followed-up regularly for an additional 16 months. His renal functions remained stable. Throughout this period he received $15 \mathrm{mg}$ prednisone on alternate days. A further reduction of the steroid dosage was attempted twice and failed because of an exacerbation of arthritic pain, especially in the knee joints. Finally an arthroplasty of the left knee was performed. On the ninth postoperative day the patient developed severe respiratory distress and died. The necropsy revealed massive pulmonary embolism. The degree of renal amyloidosis found at necropsy was fairly comparable to that seen on renal biopsy performed 3 years earlier. Amyloidosis was also found in the lungs, the intestinal submucosa, the adrenals, and the spleen.

Patients 7 and 8 were in end-stage renal failure when DMSO was started. Patient 7, a 54-year-old male, had amyloidosis secondary to chronic osteomyelitis of both legs which developed after bilateral compound fractures of the tibia and the fibula in a road accident 10 years earlier in Eastern Europe. On admission the blood urea was $200 \mathrm{mg} / \mathrm{dl}$ (33 $\mathrm{mmol} / \mathrm{l}$ ) and the residual renal function (RRF) was $9 \mathrm{ml} / \mathrm{min}$ creatinine clearance. A decline of blood urea was noted in the third month of DMSO treatment $(7 \cdot 5 \mathrm{~g} / \mathrm{day})$. The urea values stabilised around $100 \mathrm{mg} / \mathrm{dl}(17 \mathrm{mmol} / \mathrm{l})$ with RRF of $15-16 \mathrm{ml} / \mathrm{min}$ from the fifth month onwards. During the first 2 months there was a transient rise of proteinuria from $5 \mathrm{~g} / 24 \mathrm{~h}$ to $10-14 \mathrm{~g} / 24 \mathrm{~h}$. However, there was no decrease in serum albumin levels. Daily DMSO treatment was continued for 8 months without further improvement. Subsequently the patient has been maintained on supportive haemodialysis of $8 \mathrm{~h}$ per week. His sense of wellbeing was thus markedly improved. The last follow-up information on this patient was obtained 20 months after the beginning of DMSO treatment. The RRF was stable around 15 $\mathrm{ml} / \mathrm{min}$ creatinine clearance. The course of this patient is illustrated in Fig. 1.

Patient 8 had amyloidosis secondary to cavitary pulmonary tuberculosis. He was referred to us already with an A-V fistula, ready for haemodialysis. His blood urea was $280 \mathrm{mg} / \mathrm{dl}(46 \mathrm{mmol} / \mathrm{l})$, the RRF was $9.5 \mathrm{ml} / \mathrm{min}$ creatinine clearance. At the end of 7 months of oral DMSO treatment $(7.5 \mathrm{~g} /$ day) his blood urea was $90 \mathrm{mg} / \mathrm{dl}(15 \mathrm{mmol} / \mathrm{l})$ and the creatinine clearance was $25 \mathrm{ml} / \mathrm{min}$. The patient then discontinued treatment. When he returned to our clinic 7 months later his blood urea was $255 \mathrm{mg} / \mathrm{dl}$ (42 $\mathrm{mmol} / \mathrm{l}$ ) and RRF $8 \mathrm{ml} / \mathrm{min}$. DMSO was reinstituted $(10 \mathrm{~g} /$ day $)$ and a gradual improvement of renal function followed. At the end of the 7th month of the

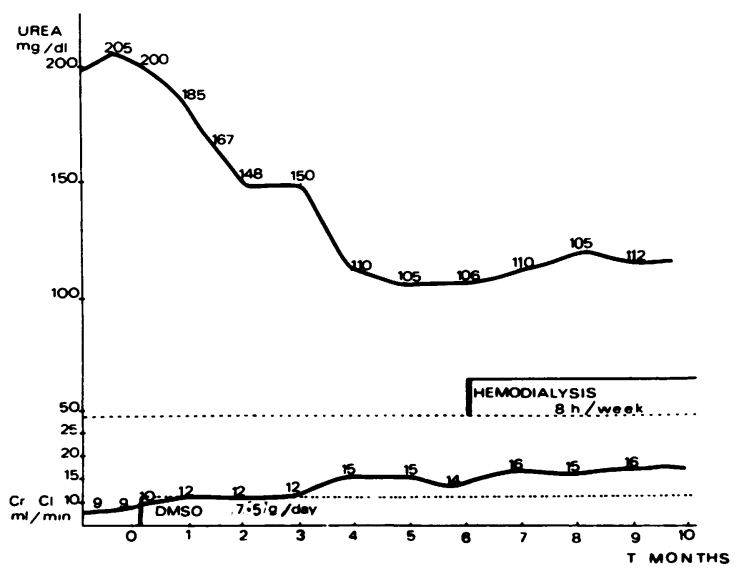

Fig. 1 Patient 7. Male, age 54. Amyloidosis secondary to osteomyelitis of both legs.

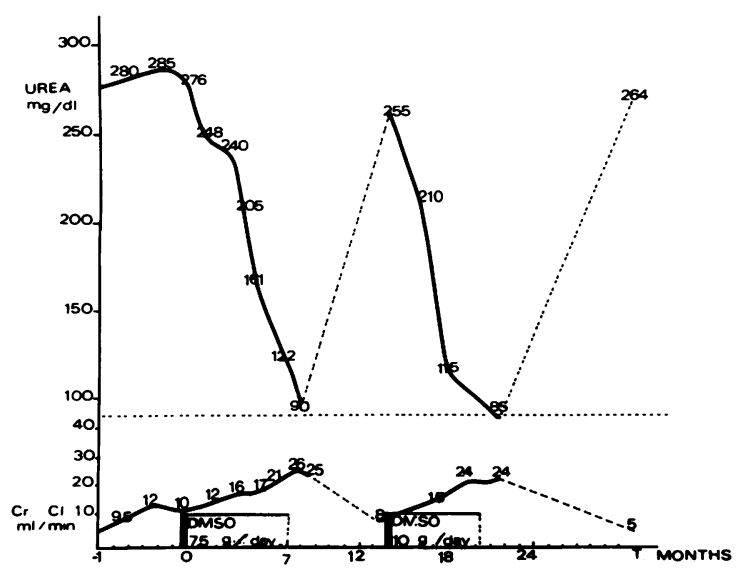

Fig. 2 Patient 8. Male, age 56. Amyloidosis secondary to cavitary pulmonary tuberculosis (inactive). 
second course the blood urea was $85 \mathrm{mg} / \mathrm{dl}$ (14 $\mathrm{mmol} / \mathrm{l}$ ), at which point the patient again chose to discontinue the DMSO. An already predicted deterioration of renal function followed. He refused to resume DMSO treatment and 9 months later received a kidney transplant (Fig. 2).

Patient 9, a male aged 65, had amyloidosis secondary to chronic obstructive lung disease with bronchiectasis of more than 20 years' duration. The blood urea values were $160-170 \mathrm{mg} / \mathrm{dl}(27-28 \mathrm{mmol} / \mathrm{l})$ with $16-18 \mathrm{ml} / \mathrm{min}$ creatinine clearance. Oral DMSO treatment $8 \mathrm{~g} /$ day brought about a gradual improvement of renal function to a nadir of $35-40 \mathrm{ml} / \mathrm{min}$ creatinine clearance at 8 months. From this point onwards renal function remained stable for an additional 6 months (Fig. 3). The patient then developed

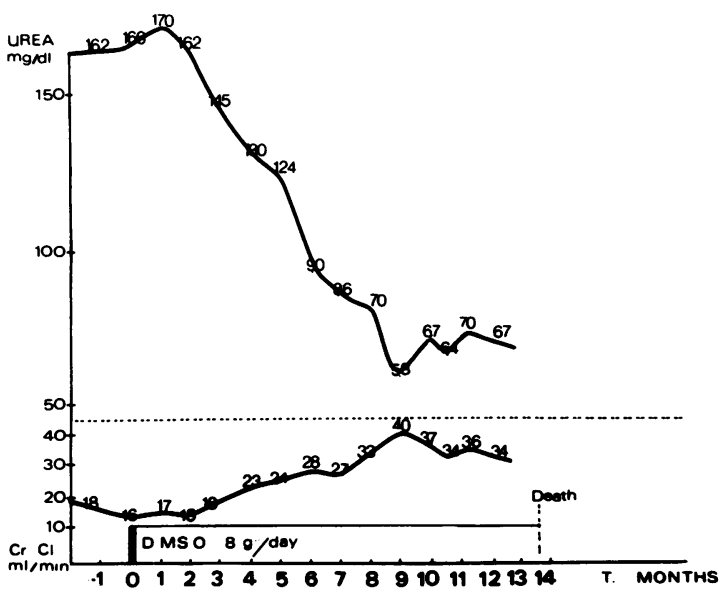

Fig. 3 Patient 9. Male, age 65. Amyloidosis secondary to chronic obstructive lung disease. Died from acute respiratory failure.

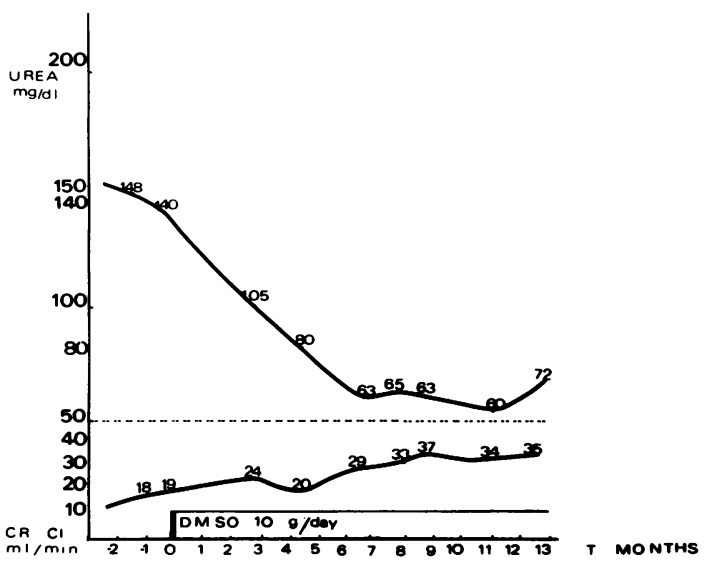

Fig. 4 Patient 10. Male, age 46. Amyloidosis secondary to ankylosing spondylitis. an acute pulmonary infection and died in respiratory failure. Permission for necropsy was refused.

Patient 10, a male aged 46, had amyloidosis secondary to ankylosing spondylitis which had been diagnosed at the age of 21 . Seven months of oral DMSO $(10 \mathrm{~g} /$ day $)$ helped to reduce the blood urea from 150 to $60 \mathrm{mg} / \mathrm{dl}(25-10 \mathrm{mmol} / \mathrm{l})$ and double the creatinine clearance from 18 to $35 \mathrm{ml} / \mathrm{min}$. The patient has remained stable for 2 years and is maintained on DMSO now reduced to $6 \mathrm{~g} /$ day taken at bedtime and alternating with nonsteroid anti-inflammatory drugs (Fig. 4).

IDIOPATHIC SYSTEMIC AMYLOIDOSIS

Three patients included in this category were 2 males aged 65 and 61 and a female aged 65 . The clinical presentation included end-stage renal failure with heavy proteinuria and extreme weakness. There were no signs of peripheral neuropathy. Echocardiographic evidence of restrictive cardiomyopathy was present in all 3 patients, and subsequently they all developed severe resistent cardiac failure with hypotension. A subnormal adrenal response to ACTH was also found in these 3 patients. The female patient also developed clinical and laboratory signs of hypothyroidism $\left(\mathrm{T}_{4}<1 \mathrm{ng} / \mathrm{ml}=1 \mathrm{nmol} / \mathrm{l}\right)$. DMSO 15 $\mathrm{g} /$ day was given to each of these patients for periods of 10,12 , and 16 months respectively. The 2 male patients showed no response. Their clinical course was downhill and death was due to cardiogenic shock. In the female patient renal functions remained stable while on DMSO (creatinine clearance $\simeq 20 \mathrm{ml} / \mathrm{min}$ ) and the cardiac failure was controlled by loop diuretics. Having felt no improvement the patient asked to discontinue the medication. A very rapid deterioration of renal function followed. Uraemia, metabolic acidosis, and intractable cardiac failure brought about death 2 months later. The necropsy revealed massive deposition of amyloid in all internal organs: the thyroid was almost totally replaced by amyloid, and the myocardium, the liver, all layers of the intestinal wall, and the kidneys were heavily infiltrated. Except for moderate arteriosclerotic changes in the coronary vessels, the aorta, and large arteries no other disease was found.

\section{UN T OW ARD EFFECTS}

DMSO was tolerated quite well by all the patients. There was a mild degree of nausea without vomiting. The visual acuity was unchanged; no patient developed cataracts or clouding of the lens. There was no evidence of haemolysis in any of the patients, and no alterations of liver enzymes, plasma proteins, divalent ions, or electrolytes occurred except when accounted for by the underlying disease. The unpleasant breath odour typical of DMSO ingestion 
was more disturbing to their families than to the patients themselves. However, it imposed a considerable degree of social isolation and was the main reason for some patients' reluctance to continue with this treatment.

\section{Discussion}

Degradation of amyloid fibrils in vitro by DMSO was first demonstrated by Isobe and Osserman, ${ }^{7}$ who have also found that DMSO caused partial resorption of casein-induced amyloidosis in mice. These results were confirmed by other laboratories, including our own. ${ }^{89}$

Three series of patients with amyloidosis treated with DMSO have thus far been reported..$^{11-13}$ Out of 17 patients with myeloma-associated amyloidosis reported by Osserman, Sherman, and Kyle ${ }^{11}$ only 8 patients received DMSO for periods longer than 6 months, and 6 of them showed some clinical improvement in terms of regression of macroglossia, decrease in liver size, and regression of neuropathy. However, all those patients were concomitantly treated with melphalan. A potentiation of melphalan effect by DMSO could thus be postulated, and these results cannot be interpreted as demonstrating an unequivocal therapeutic effect of DMSO on myeloma-associated amyloidosis. Two patients with myeloma-associated amyloidosis were included in the series reported by Van Rijswijk et al. ${ }^{12}$ The results of DMSO were inconclusive. The only patients who responded to DMSO in that series were 3 with amyloidosis secondary to rheumatoid arthritis.

The present report includes 13 patients of whom 7 showed a significant clinical response to prolonged DMSO administration. These patients had systemic amyloidosis secondary to systemic inflammatory or chronic infectious diseases. An increase of creatinine clearance, a decline in proteinuria, and regression of all parameters of the nephrotic syndrome were evident after 3-5 months of continuous treatment. The new equilibrium was maintained as long as DMSO was given. The chemical nature of amyloid fibrils in reactive systemic amyloidosis is generally assumed to be of the AA variety. The favourable effect of DMSO could therefore be expected in view of the results obtained in experimental animals with caseininduced AA amyloidosis. ${ }^{78}$ However, the mere presence of AA amyloidosis does not guarantee favourable results of DMSO since none of the FMF patients who also have AA type amyloidosis ${ }^{15}$ showed any response. The 3 patients with idiopathic (possibly monoclonal protein) amyloidosis did not respond to DMSO. Similar disappointing results were reported in 3 such patients treated by Van Rijswijk et al. ${ }^{12}$

Like others we have observed no serious untoward effects attributable to DMSO. There were no occular findings, and no haematological or biochemical abnormalities were recorded. DMSO alone is most probably nontoxic even in large doses. Its potentiating capacity on the effect of other concomitantly administered drugs must, however, be kept in mind. Our patients received various antibiotics, diuretics (thiazides, furosemide), steroids, anti-inflammatory drugs (indomethacin, ketoprofen, dipyrone, paracetamol) without side effects. Hepatotoxicity, hypotension, and paralytic ileus, all transient, were reported with the concomitant use of DMSO and other medications. ${ }^{16}$ The main problem encountered with this treatment was the need for continuous reassurance of the patients in order to overcome their reluctance to take DMSO. Some of the patients found it very difficult to cope with the social seclusion imposed upon them by the breath odour that followed DMSO ingestion. Omission of DMSO on days prior to social or religious events was only partly successful, because although the intensity of the malodorous breath was markedly reduced within 12 hours of the last ingestion the odour was clearly noticeable for the subsequent week or even longer. It is due to the continuous excretion of a small fraction of DMSO as dimethysulphite via the breath. ${ }^{17}$ Since this is a long-term and unpleasant treatment the institution of DMSO is a major therapeutic decision. The hitherto available information as well as our own experience suggests that this drug should be advocated to patients with secondary amyloidosis. The results in other types of amyloidosis have thus far been equivocal or clearly disappointing. The damage produced by amyloidosis to affected organs is only partly reversible. Therefore in patients with a far advanced disease only a stabilisation or a modest degree of improvement may be anticipated under continuous DMSO treatment. Once started, DMSO treatment should be continued for 6 months before any conclusions on its efficacy may be drawn.

The mechanism of action of DMSO on amyloidotic organs is not clear. The original assumption that it breaks down amyloid fibrils into subunits which are excreted by the kidneys finds support in the disappearance of amyloid deposits in DMSO-treated animals, ${ }^{79}$ and in the presence in the urine of amyloid subunits from which a Congo red positive amyloidlike fibrillar material can be synthesised in vitro. ${ }^{18}$ However, this material, which on immunodiffusion reacts with anti-AA serum, was found also in the urine of DMSO-treated FMF patients who did not respond clinically. Repeated biopsies in patients who responded favourably to DMSO and the necropsy findings in a few patients revealed abundant amyloid deposition in the kidneys and in other organs. Inhibition of amyloid synthesis by DMSO was suggested, ${ }^{12}$ 
since a rapid decline of sAA blood levels followed its administration. A similar decline of sAA levels was, however, observed also in patients with idiopathic amyloidosis who showed no clinical response to DMSO. The main effect of DMSO may be antiinflammatory, and the improvement of renal function may thus be due to inhibition or regression of the interstitial changes which accompany renal amyloid deposition $^{1920}$ rather than to an effect on the amyloidosis itself. This hypothesis may explain the otherwise extraordinary clinical course of our patient 8: a rapid improvement of renal function with DMSO was followed by an equally rapid deterioration on cessation of the drug. A second course of DMSO again restored renal function, which fell rapidly on interruption of treatment. These ups and downs could not possibly be accounted for by resorption and reaccumulation of amyloidosis. They therefore indicate the presence of another mechanism of action of DMSO on the kidney.

\section{References}

${ }^{1}$ Glenner G G. Amyloid deposits and amyloidosis. $N$ Engl $J$ Med 1980; 302: 1283-92, 1333-43.

2 Wegelius O, Wafin F, Falck H, Tomoroth T. Follow up study of amyloidosis secondary to theumatic disease. In: Glenner $\mathbf{G ~ G}$, Costa P P, Freitas F, eds. Amyloid and Amyloidosis. Amsterdam: Excerpta Medica, 1980: 183-90.

3 Zemer D, Prass M, Shemer Y, Sohar E, Gafni J, Daily prophylactic colchicine in familial Mediterranean fever. In: Glenner G G, Costa P P, Freitas F, eds. Amyloid and Amyloidosis. Amsterdam: Excerpta Medica, 1980: 580-3.

${ }^{4}$ Ravid M, Robson M, Kedar I. Prolonged colchicine treatment in four patients with amyloidosis. Ann Intern Med 1977; 87: 568-70.

5 Buxbaum J N, Harley M E, Chuba J, Spiro T. Amyloidosis of the AL type clinical morphologic and biochemical aspects of the response to therapy with alkylating agents and prednisone. Am J Med 1979; 67: 867-78.

6 Kyle R A, Bayrd E D. Amyloidosis: review of 236 cases. Medicine (Baltimore) 1975; 54: 271-99.
7 Isobe T, Osserman E F. Effects of dimethyl sulfoxide (DMSO) on Bence Jones proteins, amyloid fibrils and casein induced amyloidosis. In: Wegelius O, Pasternak A, eds. Amyloidosis. New York: Academic Press, 1976: 247-57.

* Kedar I, Greenwald M, Ravid M. Treatment of experimental murine amyloidosis with dimethyl sulfoxide. Eur J Clin Invest 1977; 7: 149-50.

${ }^{9}$ Hanai N, Ishihara T, Muchino F, Imada N, Fugihara Sh, Ikegami J. Effect of dimethyl sulfoxide and colchicine on the resorption of experimental amyloid. Virchows Arch (Pathol Anat) 1979; 384: 45-52.

${ }^{10}$ Greenwald M, Kedar I, Sohar E. The effect of colchicine and dimethylsulfoxide (DMSO) on the genetic amyloidosis of the white Pekin duck. In: Glenner G G, Costa P P, Freitas F, eds. Amyloid and Amyloidosis. Antsterdam: Excerpta Medica, 1980: 584-6.

11 Osserman E F, Sherman W H, Kyle R A. Further studies on therapy of amyloidosis with dimethyl sulfoxide (DMSO). In: Glenner G G, Costa P P, Freitas F, eds. Amyloid and Amyloidosis. Amsterdam: Excerpta Medica, 1980: 563-9.

12 Van Rijswijk M H, Donker A J M, Ruinen Z. Dimethyl sulfoxide in amyloidosis. Lancet 1979; i: 207-8.

13 Ravid M, Kedar I. Prolonged dimethyl sulfoxide treatment of amyloidosis in man. In: Glenner G G, Costa P P, Freitas F, eds. Amyloid and Amyloidosis. Amsterdam: Excerpta Medica, 1980: 578-9.

14 Wright J R, Calkins E, Humphrey R L. Potassium permanganate reaction in amyloidosis: a histologic method to assist in differentiating forms of this disease. Int Acad Pathol 1977; 36: 274-8.

15 Levin M, Franklin E C, Frangione B, Prass M. The amino acid sequence of a major nonimmunoglobulin component of some amyloid fibrils. J Clin Invest 1972; 51: 2773-6.

16 Yellowlees P, Greenfiels C, McIntyve N. Dimethyl sulfoxide induced toxicity. Lancet 1980; ii: 1004-6.

17 Wood D C. Fate and metabolism of DMSO. In: Jacob S W, Rosenbaum E E, Wood D C, eds. Dimethyl Sulfoxide. New York: Dekker, 1971: 133-47.

18 Ravid M, Kedar (Kaizman) I, Sohar E. Effect of a single dose of dimethyl sulfoxide on renal amyloidosis. Lancet 1977; i: 730-1.

19 Mackensen S, Grund K E, Bader A. The influence of glomerular and interstitial factors on the serum creatinine concentration in renal amyloidosis. Virchows Arch (Pathol Anat) 1977; 375: 159-68.

${ }^{20}$ Gise H V, Helmchen U, Mickeler E, et al. Correlation between morphological and clinical findings on a patient recovering from secondary generalized amyloidosis with renal involvement. Virchows Arch (Pathol Anat) 1978; 379: 119-29. 